\title{
Webtrust $^{\mathrm{Sm}}$ (Version 3.0): Evidence On Consumers' Demand For Assurance Services And CPAs' Comparative Advantage
}

Robert R. Greenberg (E-mail: greenberg@wsu.edu), Washington State University Bernard Wong-On-Wing (E-mail: wow@wsu.edu), Washington State University

\begin{abstract}
Modifications to Web Trust in version 3.0 allowing practitioners to issue an opinion on individual principles (e.g., privacy and security) enables WebTrust to compete directly against other assurance services. The success of the new strategy depends upon: (1) differences in assurance demand for the individual principles, and (2) perceptions that CPAs are the most trusted assurance provider. This study finds: (1) the need for assurance differs across individual WebTrust principles and depends upon transaction type, and (2) CPAs are not perceived to be the most trusted provider.
\end{abstract}

\section{Introduction}

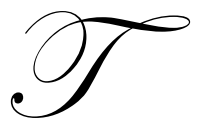

he WebTrust assurance service consists of a series of programs that are intended to alleviate consumers' concerns when transacting online. For example, consumers may be worried about the privacy of personally identifiable data that they submit to a Web site to complete an online purchase. In a WebTrust engagement, a licensed practitioner verifies whether an online business complies with principles and criteria regarding matters such as privacy, security, availability and business practices. If a business meets the WebTrust principles and criteria, it is awarded an electronic seal that can be displayed on the company's Web site. Consumers can click on the seal to view the digital certificate that authenticates the seal. In addition, they can review the report of the public accountant as well as the company's business practices.

Because of the CPA's reputation for objectivity and integrity, the accounting profession appears to have a competitive advantage in providing assurance services. To date however, demand for the WebTrust program has been very limited. At the time of this writing, the American Institute of CPAs (AICPA) WebTrust site index listed only 24 sites with the WebTrust seal. In contrast, demand for similar services offered by competitors continues to grow. For example, BBBOnline, which offers assurance seals for reliability and privacy, lists 9757 and 844 participant sites respectively for each program. This significant discrepancy is even more surprising given that WebTrust has the further advantage of covering a wider range of principles. Competing assurance providers offer programs that focus on only one or two consumer concerns. A new provision of version 3.0 of WebTrust allows practitioners to similarly issue an opinion on individual principles. An online business can now obtain assurance on a specific principle such as Privacy. This major change puts WebTrust in direct competition against other services that provide assurance about specific consumer concerns. For example, TRUSTe focuses on Privacy whereas BBBOnline provides assurance about both Privacy and Reliability.

Whether the new marketing strategy will be effective depends on the presence of at least two conditions. First, the need for assurance must differ across the various WebTrust principles. If the principles are perceived by consumers to be equally important, there is no basis for focusing marketing efforts on a particular principle more than on any other. On the other hand, if perceived importance differs across the WebTrust principles, marketing

Readers with comments or questions are encouraged to contact the authors via email. 
efforts can be directed at the more significant ones. Second, if it is determined that some principles are more important than others, consumers must perceive CPAs to be the most trusted assurance provider for those specific individual principles. Although CPAs have an established reputation for objectivity and integrity, these may not be considered to be as important as other factors such as technical competence. If that is the case and competitors are perceived to be more technically competent with respect to matters such as privacy and security, they may be more trusted than CPAs. Thus, competing directly against other assurance service providers is unlikely to be successful. This paper reports the results of a study that examined the extent to which the foregoing two conditions exist.

\section{Background and Research Questions}

In 1997, the AICPA Special Committee on Assurance Services (also known as the Elliott committee) issued its report after a study of the status of the assurance function and the opportunities for the future (AICPA 1997). The report called for the development of additional services to serve the needs of customers. It highlighted both the need for CPAs to seek new assurance services, and the importance of understanding the market for the new services (Elliott and Pallais 1997a, b, c, d).

WebTrust is one of the newly developed and marketed assurance services. It was jointly created by the AICPA and the Canadian Institute of Chartered Accountants (CICA). The current version 3.0 of WebTrust contains seven principles: Privacy, Security, Availability, Business Practices \& Transaction Integrity, Confidentiality, NonRepudiation and Customized Disclosures. A new provision now allows practitioners to issue an opinion and corresponding seal on individual principles or combinations of principles. The only exception is for the Customized Disclosures principle which must be evaluated with one of the other principles.

At the time of the present study, individual programs had been developed for only the first four principles. Consequently, the survey examined consumers' perceptions of WebTrust as it relates specifically to Privacy, Security, Availability, and Business Practices \& Transaction Integrity. The specific issues that were studied are described in the following sections.

\subsection{Demand for Assurance About WebTrust Principles}

Elliott and Pallais $(1997 b, 56)$ note that the first step in identifying a new assurance service is to focus on user needs. They add, "... assurance services that meet customers' needs will sell; those that do not will fail." In order to assess possible differences in demand for assurance about the individual principles, the survey examined three factors that may potentially affect the need for WebTrust assurance. These were consumers' concern about each principle, their perception of the likelihood of violation of each principle, and their perceived value of the WebTrust seal of assurance about each principle.

\subsubsection{Concern About WebTrust Principles}

Prior to version 3.0, WebTrust engagements could not be performed on specific principles. The new provision that allows practitioners to issue an opinion on individual principles, recognizes the possibility that consumers may have different levels of concern about the individual principles. Moreover, consumers' concern about a specific principle may vary depending on the type of online transaction. For example, a consumer may be more concerned when filing taxes online than when buying a book online because of the difference in perceived risk associated with each transaction. Thus, the first research question is:

RQ1: Do consumers have equal levels of concern about the individual WebTrust principles across different types of online transactions?

\subsubsection{Likelihood of Violation of WebTrust Principles}

A related and relevant factor that may affect demand for assurance is consumers' perception of the likelihood of violation of the individual WebTrust principles. For example, if consumers perceive the likelihood of violation of their privacy rights to be insignificant, demand for the seal of assurance about privacy is likely to be low. Conversely, demand is likely to be higher if the probability of violation is seen as significant. Although consumers 
may overestimate or underestimate the likelihood of violation of the various principles, it is their perception that is likely to influence demand for assurance. Hence, the second research question is:

RQ2: Do consumers perceive the violation of the individual WebTrust principles to be equally likely?

\subsubsection{Value of Seal of Assurance}

A third factor that may influence demand for assurance is the perceived value of the WebTrust seal. Two recent studies provide evidence of the potential value of the assurance program. A study by Hunton et al. (2000) found that financial analysts responded favorably to electronic commerce (EC) assurance such as WebTrust. EC assurance had a particularly large positive impact on earnings forecasts and stock price estimates when the risks associated with both the online vendor and the transaction outcome were relatively high. In a study of consumers, Kovar et al. (2000) found that those who pay attention to the seal have stronger intent to purchase online than those who do not notice the seal. This result suggests that, overall, consumers find the WebTrust seal to be valuable in that it alleviates concerns that they may have about transacting online. The current study examines consumers' perception of the value of the individual seals of assurance. Thus, the third research question is:

RQ3: Do consumers perceive the individual seals of assurance to be equally valuable in reducing concerns about each WebTrust principle?

\subsection{Relative Trustworthiness of Assurance Provider}

Early on, Gray and Debreceny (1998) recognized potential rivals to WebTrust. These include logo or seal programs offered by Secure Electronic Transaction (SET), BBBOnline, TRUSTe and the TruSecure Corporation through its International Computer Security Association (ICSA) Labs. SET licenses the use of the SET logo (or SET Mark) to Web sites that utilize technology that has passed its compliance testing. BBBOnline, a wholly owned subsidiary of the Council of the Better Business Bureaus, offers a Reliability seal and a Privacy seal program. TRUSTe, an independent nonprofit organization, awards a TRUSTe seal to Web sites that adhere to established privacy principles, and agree to comply with ongoing TRUSTe oversight and consumer resolution procedures. TruSecure Corporation provides certification of organizations that meet established requirements necessary to achieve and maintain security.

Although CPAs have the advantage of their reputation for objectivity and integrity, the competing assurance providers may be perceived to have superior knowledge of specific technical areas. For example, TRUSTe and TruSecure's ICSA Labs may respectively be seen as experts in privacy and security. Consequently, CPAs may not be viewed as the most trusted assurance provider. Hence, the fourth research question is:

RQ4: Which assurance provider is most trusted to provide assurance about each individual WebTrust principle?

\section{Method}

\subsection{Subjects}

Participants in this survey are comparable to those used in the study by Kovar et al. (2000). They were 217 undergraduate students enrolled in an introductory Management Information Systems course. All subjects were business students except for 18 participants who indicated that they were majoring in liberal arts. Most subjects' ages ranged from 18 to 25 . Only four were over 25 . As Kovar et al. $(2000,24)$ state, student-subjects provide a reasonable surrogate for online consumers who tend to be younger and more educated than traditional consumers.

Table 1 shows subjects' experience with the seven online transactions surveyed. In addition, 113 subjects (52\%) indicated that they had engaged in online transactions other than the seven listed. These included buying gifts, clothing and concert tickets. Overall, only nine respondents (4.1\%) had never completed online transactions of any type. 
Table 1

Participants' Experience with Online Transactions (Percentages are in parentheses.)

\begin{tabular}{|c|c|c|c|c|c|}
\hline & Never & Rarely & Sometimes & Frequently & Total \\
\hline Buying plane tickets & $\begin{array}{c}76 \\
(35 \%)\end{array}$ & $\begin{array}{c}44 \\
(20.3 \%)\end{array}$ & $\begin{array}{c}50 \\
(23 \%)\end{array}$ & $\begin{array}{c}47 \\
(21.7 \%)\end{array}$ & $\begin{array}{c}217 \\
(100 \%)\end{array}$ \\
\hline Trading stocks & $\begin{array}{c}179 \\
(82.5 \%)\end{array}$ & $\begin{array}{c}16 \\
(7.4 \%)\end{array}$ & $\begin{array}{c}13 \\
(6.0 \%)\end{array}$ & $\begin{array}{c}9 \\
(4.1 \%)\end{array}$ & $\begin{array}{c}217 \\
(100 \%)\end{array}$ \\
\hline Banking and paying bills & $\begin{array}{c}86 \\
(39.8 \%)\end{array}$ & $\begin{array}{c}47 \\
(21.8 \%)\end{array}$ & $\begin{array}{c}37 \\
(17.1 \%)\end{array}$ & $\begin{array}{c}46 \\
(21.3 \%)\end{array}$ & $\begin{array}{c}216 \\
(100 \%)\end{array}$ \\
\hline Participating in auctions & $\begin{array}{c}116 \\
(53.5 \%)\end{array}$ & $\begin{array}{c}51 \\
(23.5 \%)\end{array}$ & $\begin{array}{c}31 \\
(14.3 \%)\end{array}$ & $\begin{array}{c}19 \\
(8.8 \%)\end{array}$ & $\begin{array}{c}217 \\
(100 \%)\end{array}$ \\
\hline Buying books and CDs & $\begin{array}{c}62 \\
(28.7 \%)\end{array}$ & $\begin{array}{c}57 \\
(26.4 \%)\end{array}$ & $\begin{array}{c}65 \\
(30.1 \%)\end{array}$ & $\begin{array}{c}32 \\
(14.8 \%)\end{array}$ & $\begin{array}{c}216 \\
(100 \%)\end{array}$ \\
\hline Filing taxes & $\begin{array}{c}161 \\
(74.2 \%)\end{array}$ & $\begin{array}{c}21 \\
(9.7 \%)\end{array}$ & $\begin{array}{c}19 \\
(8.8 \%)\end{array}$ & $\begin{array}{c}16 \\
(7.4 \%)\end{array}$ & $\begin{array}{c}217 \\
(100 \%)\end{array}$ \\
\hline Buying computers & $\begin{array}{c}131 \\
(60.4 \%)\end{array}$ & $\begin{array}{c}41 \\
(18.9 \%)\end{array}$ & $\begin{array}{c}35 \\
(16.1 \%)\end{array}$ & $\begin{array}{c}10 \\
(4.6 \%)\end{array}$ & $\begin{array}{c}217 \\
(100 \%)\end{array}$ \\
\hline
\end{tabular}

\subsection{Procedures}

The survey was administered to all subjects at the same time during one class period. The time required to complete the questionnaire ranged from fifteen to twenty minutes. All subjects received extra credit for their participation.

\subsection{Questionnaire}

The survey instrument was five pages in length. The first four pages assessed participants' perceptions regarding each one of the four WebTrust principles (Privacy, Security, Availability, and Business Practices \& Transaction Integrity) that were studied. The order of these pages was alternated so that none of the principles consistently appeared first, second, third or fourth. The fifth page gathered demographic data including subjects' experience with online transactions, their major field of study, their gender and their age. Each of the first four pages contained the following:

- a description of the WebTrust principle,

- a measure of the extent of concern about the principle for seven types of online transactions,

- a measure of the perceived likelihood of violation of the principle,

- a description of examples of violations of the principle,

- $\quad$ a description of the assurance provided by the WebTrust seal for the principle,

- $\quad$ a measure of the perceived value of the seal of assurance,

- $\quad$ the choice for the most trusted assurance provider for the principle.

The appendix presents the page used to record subjects' responses with respect to Privacy. The description at the top of the page ensured that subjects understood the nature of each WebTrust principle. Subjects were then asked to indicate on a seven-point Likert scale the extent to which they were concerned about each principle for each one of the seven online transactions. The scale was labeled from 1 "not at all concerned" to 7 "extremely concerned." To address RQ1, these responses were compared to determine whether consumers have equal levels of concern about the individual WebTrust principles across different types of online transactions. Subsequently, subjects were asked to indicate on a seven-point Likert scale the likelihood that each principle may be violated. The scale was labeled from 1 "extremely unlikely" to 7 "extremely likely." These responses pertained to RQ2.

In the next part, subjects read examples of violations of the principle, and a description of the assurance provided by the WebTrust seal for the principle. The assurance description pertained to the disclosure of an entity's practices, compliance with the practices and maintenance of effective controls. Subjects were then asked to indicate on a seven-point Likert scale the extent to which a seal of assurance would reduce any concern that they may have 
about each principle. The scale was labeled from 1 "not at all" to 7 "to a great extent." These responses were compared across principles to address RQ3.

Finally, subjects were asked to select from a list, the independent party that they would trust the most to provide the seal of assurance. The choices were the Better Business Bureau, Experts in Information Technology, CPAs, a Government-Appointed Agency, a Nonprofit Organization and Some Other Party. Subjects' selections were tabulated for each principle to provide insights into RQ4.

\section{Results}

\subsection{Concern About WebTrust Principles (RQ1)}

Table 2 shows participants' level of concern about the Privacy, Security, Availability, and Business Practices \& Transaction Integrity across the seven types of transactions examined. With respect to the WebTrust principles, Availability was consistently viewed as less of a concern than Privacy, Security, and Business Practices \& Transaction Integrity. A comparison of the mean aggregate scores revealed that concern about Availability was significantly lower than concern about the other three principles $(\mathrm{p}<0.05)$. The differences in aggregate scores among Privacy, Security, and Business Practices \& Transaction Integrity were not statistically significant.

With respect to the types of transactions, the results suggest that subjects are more concerned when completing online transactions related to Filing Taxes, Banking \& Paying Bills, and Trading Stocks than when completing the other transactions. This result was consistent across all four WebTrust principles.

Table 2

Concern About Privacy, Security, Availability, and Business Practices \& Transaction Integrity Across Types of Online Transactions

(Standard deviations are in parentheses; all cells $n=217$ except where noted)

\begin{tabular}{|c|c|c|c|c|}
\hline & Privacy & Security & Availability & $\begin{array}{c}\text { Business Practices } \\
\text { \& Transaction } \\
\text { Integrity }\end{array}$ \\
\hline Buying plane tickets & $\begin{array}{l}4.35 \\
(2.02)\end{array}$ & $\begin{array}{c}4.31 \\
(2.10)\end{array}$ & $\begin{array}{c}3.58 \\
(1.85)\end{array}$ & $\begin{array}{c}4.55 \\
(1.99)\end{array}$ \\
\hline Trading stocks & $\begin{array}{c}4.81 \\
(2.01)\end{array}$ & $\begin{array}{l}4.70 \\
(2.07)\end{array}$ & $\begin{array}{l}4.00 \\
(2.24)\end{array}$ & $\begin{array}{c}4.88 \\
(1.95)\end{array}$ \\
\hline Banking \& paying bills & $\begin{array}{c}5.31 \\
(1.99)\end{array}$ & $\begin{array}{c}5.14 \\
(2.04) \\
n=216\end{array}$ & $\begin{array}{c}4.34 \\
(2.11)\end{array}$ & $\begin{array}{c}5.15 \\
(1.94)\end{array}$ \\
\hline Participating in auctions & $\begin{array}{c}4.14 \\
(1.90)\end{array}$ & $\begin{array}{c}3.93 \\
(1.88)\end{array}$ & $\begin{array}{c}3.00 \\
(1.78)\end{array}$ & $\begin{array}{c}3.99 \\
(1.80)\end{array}$ \\
\hline Buying books \& CDs & $\begin{array}{c}3.94 \\
(2.06)\end{array}$ & $\begin{array}{c}3.71 \\
(1.98)\end{array}$ & $\begin{array}{c}3.08 \\
(1.82)\end{array}$ & $\begin{array}{c}3.60 \\
(1.81)\end{array}$ \\
\hline Filing taxes & $\begin{array}{c}5.23 \\
(2.01)\end{array}$ & $\begin{array}{c}4.99 \\
(2.09)\end{array}$ & $\begin{array}{c}4.37 \\
(2.15)\end{array}$ & $\begin{array}{c}5.06 \\
(1.99)\end{array}$ \\
\hline Buying computers & $\begin{array}{c}4.00 \\
(2.00)\end{array}$ & $\begin{array}{c}3.92 \\
(2.00)\end{array}$ & $\begin{array}{c}3.31 \\
(1.84)\end{array}$ & $\begin{array}{c}4.21 \\
(2.00)\end{array}$ \\
\hline Aggregate & $\begin{array}{c}31.82 \\
(11.23)\end{array}$ & $\begin{array}{c}30.70 \\
(11.75)\end{array}$ & $\begin{array}{c}25.69 \\
(10.41)\end{array}$ & $\begin{array}{c}31.47 \\
(10.67)\end{array}$ \\
\hline
\end{tabular}

Subjects were asked to indicate on a seven-point Likert scale the extent to which they were concerned about each principle for each one of the seven online transactions. The scale was labeled from 1 "not at all concerned" to 7 "extremely concerned". 


\subsection{Likelihood of Violation of WebTrust Principles (RQ2)}

Table 3 shows the perceived likelihood of violation of the individual WebTrust principles. Consumers did not perceive the violation of the individual WebTrust principles to be equally likely $(\mathrm{F}=57.16, \mathrm{p}<0.001)$. The perceived likelihood of violation was highest for the Privacy principle (4.83). It was significantly $(\mathrm{p}<.05)$ higher than the perceived likelihood of violation of the other three principles. The perceived likelihood of a violation of the Security principle (4.01) and that for the Business Practices \& Transaction Integrity principle (3.73) were significantly $(\mathrm{p}<.05)$ higher than that for the Availability principle (3.04).

Table 3

Perceived Likelihood of Violation of WebTrust Principles (Standard deviations are in parentheses.)

\begin{tabular}{|c|c|c|c|}
\hline Privacy & Security & Availability & $\begin{array}{c}\text { Business Practices } \\
\text { \& Transaction } \\
\text { Integrity }\end{array}$ \\
\hline 4.83 & 4.01 & 3.04 & 3.73 \\
$(1.51)$ & $(1.51)$ & $(1.34)$ & $(1.37)$ \\
$\mathrm{n}=217$ & $\mathrm{n}=215$ & $\mathrm{n}=215$ & $\mathrm{n}=215$ \\
\hline
\end{tabular}

Subjects were asked to indicate on a seven-point Likert scale the likelihood that each principle may be violated. The scale was labeled from 1 "extremely unlikely" to 7 "extremely likely".

\subsection{Value of Seal of Assurance (RQ3)}

Table 4 shows the perceived value of the individual seals of assurance. Consumers did not perceive the individual seals to be equally valuable in reducing concerns about each WebTrust principle $(\mathrm{F}=16.06, \mathrm{p}<0.001)$. The results indicate that the seal of assurance program would be most beneficial in reducing concern about Privacy (4.86), Security (4.77), and Business Practices \& Transaction Integrity (4.54). Subjects perceived a significantly $(\mathrm{p}<.05)$ lower value (3.93) associated with the seal of assurance for the Availability principle.

Table 4

Perceived Value of Seal of Assurance (Standard deviations are in parentheses.)

\begin{tabular}{|c|c|c|c|}
\hline Privacy & Security & Availability & $\begin{array}{c}\text { Business Practices } \\
\text { \& Transaction } \\
\text { Integrity }\end{array}$ \\
\hline 4.86 & 4.77 & 3.93 & 4.54 \\
$(1.49)$ & $(1.41)$ & $(1.59)$ & $(1.52)$ \\
$\mathrm{n}=212$ & $\mathrm{n}=213$ & $\mathrm{n}=208$ & $\mathrm{n}=211$ \\
\hline
\end{tabular}

Subjects were asked to indicate on a seven-point Likert scale the extent to which a seal of assurance would reduce any concern that they may have about each principle. The scale was labeled from 1 "not at all" to 7 "to a great extent."

\subsection{Relative Trustworthiness of Assurance Providers (RQ4)}

Table 5 shows that for the Privacy seal of assurance, the Better Business Bureau (35.9\%) was the most trusted followed by a government-appointed agency (29\%). For the Security seal of assurance, experts in information technology $(35.5 \%)$ were the preferred choice followed by a government-appointed agency (31.8\%). Similarly, experts in technology $(50.7 \%)$ were the most trusted to independently provide the Availability seal of assurance. For the Business Practices \& Transaction Integrity seal of assurance, subjects preferred the Better Business Bureau $(40.6 \%)$. 
Table 5

Participants' Most Trusted Assurance Provider (Percentages are in parentheses.)

\begin{tabular}{|c|c|c|c|c|}
\hline & Privacy & Security & Availability & $\begin{array}{c}\text { Business Practices } \\
\text { \& Transaction } \\
\text { Integrity }\end{array}$ \\
\hline Better Business Bureau & $\begin{array}{c}78 \\
(35.9 \%)\end{array}$ & $\begin{array}{c}47 \\
(21.7 \%)\end{array}$ & $\begin{array}{c}55 \\
(25.3 \%)\end{array}$ & $\begin{array}{c}88 \\
(40.6 \%)\end{array}$ \\
\hline CPAs & $\begin{array}{c}8 \\
(3.7 \%)\end{array}$ & $\begin{array}{c}7 \\
(3.2 \%)\end{array}$ & $\begin{array}{c}4 \\
(1.8 \%)\end{array}$ & $\begin{array}{c}15 \\
(6.9 \%)\end{array}$ \\
\hline Government-appointed agency & $\begin{array}{c}63 \\
(29 \%)\end{array}$ & $\begin{array}{c}69 \\
(31.8 \%)\end{array}$ & $\begin{array}{c}28 \\
(12.9 \%)\end{array}$ & $\begin{array}{c}40 \\
(18.4 \%)\end{array}$ \\
\hline $\begin{array}{l}\text { Information technology } \\
\text { experts }\end{array}$ & $\begin{array}{c}46 \\
(21.2 \%)\end{array}$ & $\begin{array}{c}77 \\
(35.5 \%)\end{array}$ & $\begin{array}{c}110 \\
(50.7 \%)\end{array}$ & $\begin{array}{c}61 \\
(28.1 \%)\end{array}$ \\
\hline Non-profit organization & $\begin{array}{c}20 \\
(9.2 \%)\end{array}$ & $\begin{array}{c}14 \\
(6.5 \%)\end{array}$ & $\begin{array}{c}19 \\
(8.8 \%)\end{array}$ & $\begin{array}{c}12 \\
(5.5 \%)\end{array}$ \\
\hline Other & $\begin{array}{c}2 \\
(0.9 \%)\end{array}$ & $\begin{array}{c}3 \\
(1.4 \%)\end{array}$ & $\begin{array}{c}1 \\
(0.5 \%)\end{array}$ & $\begin{array}{c}1 \\
(0.5 \%)\end{array}$ \\
\hline Total & $\begin{array}{c}217 \\
(100 \%)\end{array}$ & $\begin{array}{c}217 \\
(100 \%)\end{array}$ & $\begin{array}{c}217 \\
(100 \%)\end{array}$ & $\begin{array}{c}217 \\
(100 \%)\end{array}$ \\
\hline
\end{tabular}

Subjects were asked to select who they trusted the most to be able to independently provide the seal of assurance for each one of the four WebTrust principles.

\section{Discussion and Implications}

The purpose of this study was to examine (1) the extent to which there are differences in the demand for assurance for the various individual principles, and (2) the extent to which consumers perceive CPAs to be the most competent assurance provider for each of the specific individual principles. With respect to the first objective, the results suggest that the degree of concern is different for each WebTrust principle. Of the four principles studied, Availability is consistently viewed as being less of a concern than the other three principles. Moreover, the level of concern for each principle is dependent upon the type of online transaction. For example, Business Processes \& Transaction Integrity is the most important principle when buying plane tickets whereas Privacy is the most important when banking and paying bills, and filing taxes.

Differences were also observed in the likelihood of violation of each principle. Privacy (Availability) was perceived to be the most (least) likely principle to be violated. Consumers also saw differences in the value of the individual seals of assurance. The Privacy (Availability) seal was perceived to have the most (least) value in terms of reducing consumer concerns. Taken together, these findings consistently suggest that consumers have different needs for assurance depending on the nature of transactions. Thus, the results appear to justify the change made in version 3.0 of WebTrust that allows practitioners to issue an opinion on individual principles or combinations of principles.

With respect to the second objective, the study reveals that CPAs are not perceived to be the most trusted provider of WebTrust assurance services. BBBOnline is the most trusted for providing assurance about Privacy, and Business Practices \& Transaction Integrity. Experts in technology are the most trusted to independently provide assurance about Security and Availability. This is in sharp contrast to the initial belief that, because of their established reputation, CPAs would have the advantage in providing new assurance services such as WebTrust. Consumers do not appear to value integrity and objectivity as much as would have been expected. Alternatively, they may not perceive that CPAs integrity and objectivity extend to the new assurance services. Although the present study did not examine the specific reasons why other parties are more trusted, it is possible that consumers focus on other factors such as technical competence. The problem does not seem to be with the CPA's reputation for integrity and objectivity. Rather the lack of the CPA's reputation in other fields appears to be limiting the demand for WebTrust. This view is consistent with the current call to rebrand the profession. Thus, while some practitioners support the creation of a new interdisciplinary global credential, others prefer stretching the CPA brand to encompass a wider range of services (Snyder 2001). The finding that CPAs are not the most trusted assurance provider underscores the importance of the current call for rebranding the public accounting profession. 


\section{Suggestions for Future Research}

The findings of the present study suggest several avenues for future research directed at improving the match between WebTrust and its market. First, the present study established that the degree of concern about the individual WebTrust principles is dependent upon the type of online transaction. Future studies should investigate the specific nature of consumers' concern and its relationship to different categories of transactions. This would enable the individual WebTrust programs to be targeted at specific businesses or industry segments. Second, the present study was limited to the examination of only four WebTrust principles and seven types of transactions. Moreover, subjects (young and college-educated consumers) represented only one segment of the potential market. Future research can examine other principles and other types of online transactions within other market segments. Third, future studies should identify the specific reasons why CPAs are not perceived to be the most trusted assurance provider. Such findings would guide future efforts at rebranding the profession. Fourth, research should examine other factors that may explain the limited demand for WebTrust. For example, Arnold et al. (2000) suggest that the traditional binary audit reporting model may not provide adequate information to justify the cost of the new assurance services. Studies should examine how alternative reporting structures can provide more informative reports to consumers of assurance services. Fifth, similar studies should be conducted to provide insights into the demand for other new assurance services including SysTrust. Results of the foregoing suggested research can provide insights that may enhance the likelihood of success of new assurance services. The present study was a first step in that direction.

Notes 
Appendix

Privacy

People who are concerned about privacy are worried about how a company will use personally identifiable information that they submit to the company's Web site. Such information may include their name, address, telephone number, email address and credit card number. Without their consent, the personal data that they input on a Web site may be sold to other companies for a variety of uses. Below, circle a number to indicate how concerned you would be about the Privacy of personally identifiable data that you submit for each of the following types online transactions:

\section{Buying plane tickets}

Trading stocks

Banking and Paying bills

Participating in auctions

Buying books and CDs

Filing your taxes

Buying a computer

$$
\begin{aligned}
& \text { not at all concerned 1--- 2--- 3--- 4--- 5--- 6--- } 7 \text { extremely concerned } \\
& \text { not at all concerned 1--- 2--- 3--- 4--- 5--- 6--- } 7 \text { extremely concerned } \\
& \text { not at all concerned 1--- 2--- 3--- 4--- 5--- 6--- } 7 \text { extremely concerned } \\
& \text { not at all concerned 1--- 2--- 3--- 4--- 5--- 6--- } 7 \text { extremely concerned } \\
& \text { not at all concerned 1--- 2--- 3--- 4--- 5--- 6--- } 7 \text { extremely concerned } \\
& \text { not at all concerned 1--- 2--- 3--- 4--- 5--- 6--- } 7 \text { extremely concerned } \\
& \text { not at all concerned 1--- 2--- 3--- 4--- 5--- 6--- } 7 \text { extremely concerned }
\end{aligned}
$$

In your opinion, what is the likelihood that in e-commerce, without your consent, information about you maybe disclosed to a third party or used for purposes other than that for which it was originally intended?

$$
\text { Extremely unlikely } 1 \text {------ } 2 \text {------ } 3 \text {------ } 4 \text {------ } 5 \text {------ } 6 \text {------ } 7 \text { Extremely likely }
$$

Concern over privacy has grown following major privacy policy changes made on some popular Web sites. For example, last September, online retailer Amazon.com revised its privacy policy to allow the disclosure of personal customer information to third parties. More recently, online market place eBay received complaints after it reversed customers' previously selected preference to not get called by telemarketers.

One possible solution to reduce privacy concerns is to have an independent party evaluate and test whether a company (1) discloses its online privacy practices, (2) complies with such privacy practices, and (3) maintains effective controls to provide reasonable assurance that personally identifiable information obtained in e-commerce is protected in conformity with its disclosed privacy practices. To indicate that a company has met the foregoing conditions, a seal of assurance would be displayed on the company's Web site. To what extent would such a seal of assurance reduce any concern that you may have about privacy?

$$
\text { not at all } 1 \text {------ } 2 \text {------ } 3 \text {------ } 4 \text {------ } 5 \text {------ } 6 \text {------ } 7 \text { to a large extent }
$$

In your opinion, which one of the following would you trust the most to be able to independently provide the above seal of assurance? PLEASE SELECT ONE ONLY.

The Better Business Bureau Certified Public Accountants A Nonprofit Organization
Experts in Information Technology

A Government-appointed Agency

Some other party (Specify: 


\section{References}

1. American Institute of Certified Public Accountants, Report of the Committee on the Future of Assurance Services, AICPA, New York, NY, 1997.

2. Arnold, V., J. C. Lampe, J.J. Masselli, and S. G. Sutton, “An Analysis of the Market for Systems Reliability Assurance Services," Journal of Information Systems (Supplement), pp. 65-82, 2000.

3. Elliott, R.K. and D. M. Pallais.. "Are You Ready for New Assurance Services," Journal of Accountancy, pp. 47-51, June 1997a.

4. Elliott, R.K. and D. M. Pallais, "First: Know Your Market," Journal of Accountancy, pp. 56-63, July 1997b.

5. Elliott, R.K. and D. M. Pallais, "Build on Your Firm's Strength,” Journal of Accountancy, pp. 53-58, August $1997 \mathrm{c}$.

6. Elliott, R.K. and D. M. Pallais, “To Market, To Market We Go,” Journal of Accountancy, pp. 81-86, September $1997 \mathrm{~d}$.

7. Gray, G. L. and R. Debreceny, "The Electronic Frontier," Journal of Accountancy, pp. 32-38, May 1998.

8. Hunton, J. E., T. Benford, V. Arnold and S. G. Sutton, "The Impact of Electronic Commerce Assurance on Financial Analysts' Earnings Forecasts and Stock Price Estimates," Auditing: A Journal of Practice \& Theory (Supplement), pp. 5-22, 2000.

9. Kovar, S. E., K. G. Burke and B. R. Kovar, "Consumer Responses to the CPA WebTrust Assurance," Journal of Information Systems, pp. 17-35, Spring 2000.

10. Snyder, A., “CPAs Speak Up on the Global Credential,” Journal of Accountancy, pp. 41-47, May 2001. 